\title{
Plump or Corpulent? Lean or Gaunt? Historical Categories of Bodily Health in Nineteenth- Century Thought
}

\author{
David J. Hutson
}

\begin{abstract}
Although "excess" weight today is usually associated with poor health, nineteenthcentury classifications present an interesting historical puzzle: Physician concern with "corpulence," on the one hand, was balanced by praise for "plumpness," on the other. This is quite different from contemporary understandings of weight, where the focus is overwhelmingly on overweight and obesity. Through an analysis of nineteenth-century medical, health reform, and popular journals, I find that there was concern with weight on both ends of the spectrum - thin bodies and fat bodies were potential states of health, as well as illness, through the categories of plumpness, corpulence, leanness, and gauntness. In this way, body weight held multiple symbolic positions up until the early twentieth century when plumpness receded as a category of health. Such findings problematize the standard historical narrative of valued-to-stigmatized fatness, and suggest that the symbolic position held by body weight constitutes a more complicated phenomenon than previously believed.
\end{abstract}

\section{Introduction}

In many contemporary societies, carrying "excess" weight is widely considered to be both unhealthy and potentially stigmatizing. While scholars still debate the health consequences of body weight (Allison et al. 1999; Flegal et al. 2005; Mokdad et al. 1999), there is much consensus documenting the social consequences (Puhl and Heuer 2009). For example, studies have shown that bodily fatness impacts status in friend groups (DeJong 1980), opportunities in the workplace (Kwan and Trautner 2011), and chances in the dating and marriage markets (Crandall 1994). This stigmatization occurs primarily due to the symbolic position held by fatness today, where outer appearance is read as a sign of a person's moral and social worth (Dion et al. 1972; Hutson 2013; Saguy and Gruys 2010). Such assumptions influence interactions in a variety of contexts, and have been linked to both individual prejudice and more overt forms of employment discrimination (Hamermesh 2011; Rhode 2010).

In contrast to the generally negative view of "excess" body weight today, scholars note that fatness was regarded positively in the past, as it indicated either wealth or health, and often both (Green 1986; Stearns 1997). These accounts have been supported by research suggesting that fatness was widely valued in the nineteenth century, even becoming fashionable as an appearance ideal for women in the form of

I would like to thank the editors and anonymous reviewers at Social Science History for their support and helpful input on this manuscript. I am also grateful to Karin Martin, Howard Kimeldorf, Carla A. Pfeffer, Jacqueline Clark, Michelle Janning, Alissa Cordner, Keith Farrington, Kim Greenwell, and Alexandra Gerber for feedback on earlier drafts of this article. 
voluptuousness (Dinh 2012). While this bodily "plumpness" was indeed praised by the fashion world, it was also extolled by nineteenth-century physicians who associated a plump figure with good health. However, this more positive view of fatness receded at the beginning of the twentieth century, as interest in slimming techniques and weight reduction took hold (Czerniawski 2007; Schwartz 1986). Spurred by a cultural fascination with efficiency and scientific management (Haber 1964), and driven by growing anxieties over excess and abundance in US society (Schwartz 1986), reducing one's weight and monitoring diet became taken-for-granted norms in the early 1900s. Thus, scholars suggest that Western societies gradually transitioned from valuing plumpness to stigmatizing fatness.

What troubles this historical narrative, however, are the many warnings against body fat throughout the nineteenth century. Physicians and laypeople alike wrote regularly about the unhealthy state of "corpulence," illustrated by Banting's (1864) popular pamphlet, Letter on Corpulence. Such texts existed alongside numerous physician reports and medical essays praising plumpness. But, given that doctors did not regularly weigh patients or measure bodily fat in this time period ${ }^{1}$ (Czerniawski 2007), there is little evidence as to what these different states may have looked like. In some cases, people were proclaimed to be healthy and vibrant because they were fat, and in other cases they were proclaimed to be unhealthy and debilitated because they were fat. How these two seemingly disparate diagnoses sat side by side in the same era constitutes an interesting historical question.

In this essay, I ask: How was body weight—-both fatness and thinness-correlated with health in the nineteenth century? Why were some body weights understood as health issues, while others were constructed as beneficial? Through an in-depth, qualitative analysis of nineteenth-century medical journals, popular journals, and health reform literature, I find that individuals concerned themselves with body weights on both ends of the spectrum - thin bodies and fat bodies were potential medical problems through the categories of "gauntness" (thinness resulting in a low state of health) and "corpulence" (fatness resulting in a low state of health). Just as both thinness and fatness could indicate unhealthiness, they could also designate healthiness: Being "plump" was just as much a desired state as being "lean." In this way, body weight was allowed to hold multiple symbolic positions, with thinness and fatness understood as both positive and negative. Such findings challenge the dominant narrative implying that fatness was primarily valued in the nineteenth century, and illustrates how medical opinion on this issue was far from unanimous.

1. Scholars note that doctors did not regularly weigh patients until the 1880s (Czerniawski 2007; Stearns 1997), and personal weighing did not occur until bathroom scales became common household items in the 1910s and 1920s (Schwartz 1986). However, the connection between body weight and body size (fatness and thinness) was already ingrained in the nineteenth-century mind-set, with diet and exercise manuals providing tips for weight reduction, even without a reliable means of determining actual pounds lost (Green 1986). Thus, losing or gaining body weight was synonymous with changing one's body size. Therefore, throughout the manuscript I use the term body weight interchangeably with fatness and thinness due to its position in nineteenth-century culture as a proxy for body size. 


\section{Fatness as a Social Problem}

Much of what is written about historical conceptions of fatness suggests that it occupied a position of esteem until its construction as a social problem in the 1900s. Throughout the 1800s, people had become increasingly anxious about what types of food they put into their bodies, illustrated by the popularity of Sylvester Graham's vegetarian health reform program (Schwartz 1986). Stearns (1997) argues that multiple factors made diet a primary concern of individuals in this time period, although the term dieting did not become synonymous with weight loss until the 1910s. As many sources note, being plump was often seen as a sign of health or wealth, as it signified freedom from disease and enough money to afford not only regular, but ample meals (Farrell 2011). Fashion trends also supported the ideal of voluptuousness, with women using corseting to accentuate their hips and bosom (Dinh 2012). Accounts of exercise and physical activity also praised the stout and sturdy body (Park 1989), and many studies rely on this historical fact to frame contemporary analyses of body weight. Thus, scholars have illustrated the valued position held by fatness throughout much of the nineteenth century.

This positive evaluation of fatness, however, changed in the early 1900s when Western cultures experienced a dramatic turn toward thinness as an ideal. Researchers note a variety of factors influencing this shift, including fashion, medicine, politics, and science. While voluptuousness continued to hold sway in women's fashion until the late 1800s, by the early 1910s extreme thinness was in vogue, exemplified by the "Gibson Girl" with her exceptionally trim waist and pinned-up, yet tousled, hair (Banner 1983). Politics, too, played a role in supporting thinness as an ideal, particularly as the United States became concerned with excess in all forms. Quoting economist David A. Wells, Schwartz (1986) notes that "the country was hurting 'not because we have not, but because we have; not from scarcity, but from abundance'.... The problem was overproduction and underconsumption" (85). As the political tide turned toward skepticism of abundance, cartoonists used fatness as a metaphor for excess in governance, and the "fat cat" politician became a staple of visual satire (Farrell 2011).

Science and medicine also reflected and perpetuated this turn toward thinness. Frederick Taylor's (1911) science of efficiency, known as "scientific management" or "Taylorism," changed the way that people operated in factories and offices across the country. Photographing workers' movements and determining the most efficient way to, for example, manufacture an item on an assembly line, became an obsession within the burgeoning consumer economy (Haber 1964). Concern with efficiency even trickled down to the home, spurring the "home economics" movement, which sought to curb excesses in food consumption and household budgets (Levenstein 2003). Also, medical advances in antibiotics meant that people were enjoying much longer lives, and issues such as cancer and heart disease, rather than infectious illnesses, became more pressing (Schwartz 1986). Because of this, insurance companies constructed height-weight tables in the early 1900s to determine policyholders' longevity, and therefore, their rates for insurance (Czerniawski 2007). After Dr. Brandreth Symonds 
noted a connection between heavier policyholders and early death in 1908 (Czerniawski 2010; Symonds 1908), medical thought quickly coalesced around the idea that body fat was deadly, and the idea of how individuals might possess "excess" weight above a standardized norm took hold throughout the 1920s, 1930s, and 1940s (Czerniawski 2007; Schwartz 1986).

In this way, fatness was constructed to be a distinct medical and social problem in the early twentieth century. Similar to how extreme thinness transitioned from its association with spirituality into the disease of anorexia (Brumberg 1988), fatness came to indicate unhealthiness and lower life expectancy in the form of "obesity" (Czerniawski 2007). As is often the case with behaviors considered to be deviant, such problems become "medicalized" (Conrad and Schneider 1992) — that is, understood in medical terms and discussed in the language of disease or disorder. Indeed, the vitriol with which antifat sentiment arose at the turn of the century suggests that it had emerged as a medicalized social problem in need of solving. Drugs, diets (now indicating weight loss), and exercise regimens were all brought to bear on "excess" body weight (Schwartz 1986). By the 1950s, anxiety over fatness had become so common that Time magazine was able to publish articles with headlines such as "34 Million Fatties" (1953) and "Fat \& Unhappy" (1952) with a degree of assurance that such headlines would grab the attention of their readers. Solutions to this national problem, the writers suggested, involved eating slowly, drinking hot water with lemon, exercising throughout the day (even at work), and monitoring by physicians. Thus, the construction of fatness as a medical problem transformed it into a pressing social issue that required the intervention of multiple institutions.

Clearly, scholars have illustrated that bodily fatness moved from valued in the past to stigmatized in the twentieth century. While this narrative of "valued to stigmatized fatness" is useful for analyzing its symbolic position in contemporary society, it simultaneously obscures the connections between fatness, thinness, and health operating in the nineteenth century. For example, Farrell's (2011) excellent book on fat and modernity briefly acknowledges the earlier concern, but conflates fatness with corpulence: "As such, fatness was often linked to a generalized sense of prosperity, distinction, and high status. The corpulence itself was not represented as bad, but rather as a sign of how much the rich person had" (27). Also, only locating fatness as a social problem due to medicalization beginning in the early 1900s downplays the degree to which body size was already under the purview of doctors in the Victorian era. What is needed is a more accurate, if somewhat more complicated, picture of embodiment in the nineteenth century. As the present analysis will show, fatness was not only valued throughout the 1800 s-it occupied multiple symbolic positions up until the early twentieth century when indeed, as scholars suggest, it lost its generally positive valence. Corpulence, plumpness, leanness, and gauntness operated as distinct health categories and functioned to provide both positive and negative states of bodily well-being. To better illustrate the multiple meanings of body weight and health in the nineteenth century, I conduct a qualitative analysis of journals and pamphlets published throughout the 1800s. 


\section{Methods}

Data for this study were gathered from nineteenth-century medical journals, popular press journals, and health reform literature. During this period, and for much of the early twentieth century, journals, magazines, and pamphlets were the primary sources of information for experts and laypeople alike (Tebbel and Zuckerman 1991). Although journals initially catered to elite audiences, specifically targeting art collectors or relaying news from Europe, the United States developed its own publishing reputation during the Revolutionary War, spurred by a growing sense of national pride (ibid.). Coupled with a rise in literacy rates during the early 1800 s due to the development of institutionalized education (de Castell et al. 1986), and technological innovations like the cylindrical press, the US population was primed for reading material on a mass scale. Within approximately 25 years, from 1825 to 1850 , the number of magazines skyrocketed from 100 to 600 stable titles, with anywhere from 4,000 to 5,000 magazines starting up and quickly failing (Tebbel and Zuckerman 1991). Because of their prominence and importance in this time period, journals and pamphlets constitute excellent sources for historical and social research.

To capture a wide variety of thought on health and body weight, I utilized both long-running and shorter duration publications from three different categories: medical journals, popular press journals, and health reform literature. Drawing from a varied collection of sources allowed for seeing how body weight was discussed in different institutional settings. While the general public consumed both popular press journals and health reform literature, medical journals were usually aimed at an educated, professional audience. Yet, articles published in medical journals were often reprinted in popular press journals, illustrating how knowledge was distributed across a wide spectrum of readers. Medical journals, however, usually did not overlap in content with health reform literature. The variegated health reform movement, although widely popular among nineteenth-century individuals seeking to improve their health, was a target for physicians and doctors trying to professionalize the medical industry (Conrad and Schneider 2005). Continually wary of "quacks" peddling ineffective home remedies or espousing health knowledge mixed with moralism (as with Sylvester Graham, John H. Kellogg, and others known as "Christian Hygienists"), doctors drew boundary lines around what constituted legitimate medicine to bolster their professional standing and control of the field (Conrad and Schneider 2005; Porter 1988). Thus, medical, popular, and health reform journals all vied for readers' attention in this time period and are useful sources for understanding a wide array of views on body weight.

As noted previously, many journals began and then ended abruptly, even if considered to be influential at the time. To account for gaps in coverage, I searched within the American Periodical Series Online (APS) database (a collection of more than 1,800 journals published between 1740 and 1940), as well as within specific medical journals that spanned most of the nineteenth century. For example, although the Journal of Health was only published from 1829 to 1833, The Boston Medical and Surgical Journal ran continuously from 1828 to 1927. Similarly, The Medical News 
TABLE 1 Historical sources by type, date, and database

\begin{tabular}{|c|c|c|}
\hline Type & Date & Database \\
\hline \multicolumn{3}{|l|}{ Medical Journals } \\
\hline The American Journal of the Medical Sciences & 1820-present & AJMS database \\
\hline The Boston Medical and Surgical Journal ${ }^{\mathrm{a}}$ & $1828-1927$ & NEJM database \\
\hline Journal of Health & $1829-33$ & APS \\
\hline Medical and Surgical Reporter & $1858-98$ & APS \\
\hline The Medical News & $1869-71$ & APS \\
\hline Journal of the American Medical Association & 1883-present & JAMA database \\
\hline \multicolumn{3}{|l|}{ Popular Press Journals } \\
\hline Saturday Evening Post & 1821-present & APS \\
\hline Prairie Farmer & 1841-present & APS \\
\hline Scientific American & 1845-present & APS \\
\hline \multicolumn{3}{|l|}{ Health Reform Publications } \\
\hline The Graham Journal of Health and Longevity & $1837-39$ & APS \\
\hline The Water-Cure Journal & $1845-61$ & APS \\
\hline "On Corpulence" by William Banting & 1864 & \\
\hline "How to Be Plump" by T. C. Duncan & 1878 & \\
\hline
\end{tabular}

${ }^{a}$ The Boston Medical and Surgical Journal was retitled to The New England Journal of Medicine (NEJM) in 1928, and archival issues are in the NEJM database.

circulated from 1869 to 1871, while The American Journal of the Medical Sciences has run from 1820 to the present (see table 1).

Search terms were derived from a previous study of exercise in the nineteenth century (Hutson 2009). This earlier research utilized data from nine different educational, medical, and popular press journals published from 1815 to 1900 and resulted in a total sample of 432 articles. While immersing myself in discussions of exercise, it became clear that doctors, educators, and laypeople were using particular language to describe body weight-sometimes positively and sometimes negatively. Yet, the words they used were not always consistent, and covered a range of bodily states. I compiled a list of the most common terms I encountered, as well as additional terms I knew were popular during this time period, to explore the meaning of body size. Within APS or the specific journal's database, I employed the following terms: lean/leanness, slender, thin, gaunt/gauntness, emaciated/emaciation, obese/obesity, corpulent/corpulence, embonpoint, and plump/plumpness. In some cases, such as with the term thin, I paired it with the words health or weight to better target articles dealing with body weight, rather than essays discussing thin blood, for example. Similarly, the term plump was usually paired with health or weight to pinpoint discussions where physicians were referencing plump as an assessment of health. All search returns' titles and abstracts were scanned for relevance, and articles were coded according to how the terms were being employed. Using this method, I collected and analyzed 134 articles from 11 journals and two pamphlets published throughout the nineteenth century.

Although content analysis usually involves a more quantitative counting of data, I utilized Altheide's (1996) method of qualitative content analysis whereby each source is read carefully to develop thematic codes. This process entails what Altheide 
refers to as emergence, or "the gradual shaping of meaning through understanding and interpretation" (10) that involves a comparison of texts over time. Altheide's technique aligns with traditional qualitative analysis where researchers first inductively create codes (Strauss and Glaser 1967), which are then more deductively applied to highlight patterns in the data (Emerson et al. 1995). Employing this method produced numerous, broad categories that included themes such as warnings against gauntness; plumpness as indicating positive health; corpulence and illness; and praise for leanness. Similar to the benefits associated with textual or "discourse analysis" (Fairclough 2013), this technique allows researchers to gain a more nuanced understanding of social phenomena that is sensitive to both history and context.

\section{Historical Contexts of Body Weight}

Throughout much of the 1800 s one could be considered healthy regardless of body weight, and Victorian medicine supplied categories for individuals who were thin and healthy (lean), as well as for people who were fat and healthy (plump). By the same token, doctors also stayed alert for negative states of health associated with body weight when one was either thin and unhealthy (gaunt) or fat and unhealthy (corpulent). Thus, fatness was not unilaterally valued in the past and occupied two distinct symbolic positions - one that was praised, and one that was stigmatized. Peering into nineteenth-century journals provides insight into how these categories functioned in that time period.

\section{Plumpness}

The bodily state of plumpness received much attention in medical journals throughout the 1800 s, primarily due to the potential scarcity of food in most rural and industrializing societies (Schwartz 1986). Accordingly, plumpness became important not because it indicated wealth necessarily, but because it meant that the body was taking in proper nutrition. Plumpness, however, was not just fatness. As Dr. James Paul (1865) explains in his article "The Food and the Teeth":

\footnotetext{
Again, it may be contended that among the beautiful children we see on every hand, there is no want of those who are fat and hearty. It is not fat we want-it is bone and muscle-with so much fat only as shall give firmness to the flesh and plumpness to the figure. (6)
}

The differentiation between wanted and unwanted fat is telling - bodily fat that creates a firm and plump physique is advantageous, while extraneous fat is not. Plumpness was also used as a synonym for a general assessment of health, as Dr. Stahlberg (1877) illustrates in an article about an innovative treatment at the Kumyss Institute in Moscow: 


\begin{abstract}
After a six weeks' kumyss treatment, with a quantity of two bottles per day, patient had recovered in a degree eliciting the profound astonishment of those of her relatives that had eagerly watched the treatment; her complexion having assumed a healthy appearance, her cheeks being decked with a rosy hue, while her former bony form had changed into a plumpness, making her appear many years younger. (144)
\end{abstract}

Here, plumpness signals a return to health from a previous emaciated state. What is perhaps most striking from a contemporary standpoint is the notion that gaining a plump appearance might make one look younger, as contemporary ideals routinely link thinness with youth and beauty.

Similarly, Dr. John Ashburner (1833) in his essay on the "Medicinal Virtues of the Smilax Aspera," invokes plumpness to indicate that an herbal treatment has cured sickness:

I have been putting smilax to another use. I have had in the hospital three severe cases of venereal. I put them under a course of it.... All rapidly improved. The ulcers healed beautifully; and one of the patients who came into the hospital an emaciated, poor, thin, dying devil, soon, under this medicine, became plump and fat.... In most cases, the use of smilax aspera, like that of sarsaparilla, has been attended with a beneficial change in the condition of the patient; plumpness, clearness, and strength, succeeding to emaciation, muddiness, and debility. (01)

In this passage, plumpness is contrasted with negative states of health deriving from venereal disease, where patients were wasting away from illness. In this sense, plumpness was understood as beneficial when replacing extreme thinness.

Although often at odds with the dominant medical establishment, even health reformers considered plumpness to be virtuous. In the pamphlet How to Be Plump (1878), Dr. T. C. Duncan writes:

\begin{abstract}
The importance of fat are physical, mental and moral. A child well nourished, fat, and fair, grows rapidly and develops easily and finely; while a child thin in flesh (fat) grows feebly and develops poorly and with a struggle. A feeble girl or boy is almost certain to develop early and prematurely, and like premature fruit early and easily decays. The organs are poorly nourished, there is not fat in the abdomen and the form bends and contracts as in old age, while the fleshy body stands nobly erect and has a royal mien. (44)
\end{abstract}

Duncan, a clear advocate of fleshiness, tapped into widespread anxieties about frail children who were thought to grow weak from life in the industrial city (Park 1989). But, health reformers also drew on fears of aging - usually to promote their own health systems. In this passage, the author contrasts elderly people in the United States with older Europeans using imagery involving plumpness: 


\begin{abstract}
Old men among us are almost invariably lean and dried up, or burdened with gross fat. The preservation of a fresh, ruddy complexion, softened down by the intermingling of neutral tints into a mellow, harmonious coloring, with a bright, clear eye, erect graceful carriage, thick, flowing hair, powdered it may be with silver, and plumpness that suffices to give a just and becoming roundness to the contour of the figure, are almost unknown among our countrymen past the middle age. ("Eating" 1847: 322)
\end{abstract}

Clearly, both the young and the old were thought to benefit from the guidance of health reformers when restoring a plump physique.

Popular journals occupied an interesting position in the nineteenth century, often functioning as a conduit for medical knowledge and health reform ideologies simultaneously. Usually, this involved relaying information in a more narrative, accessible tone that appealed to readers by intermingling advice, news, and fictional stories. For example, one Saturday Evening Post article commented on advice from a "Prof. Blot," who explained the association between food and plumpness:

Any one, male or female, young or old, starting with a good stomach, can keep healthy and in good flesh with proper food; it is only necessary to select the kind required by the constitution, and prepare it judiciously. It is not what we eat that makes us fat, but what we digest. Bad food may bring a temporary bloatedness, but not the plumpness of good health. ("Remarks on Eating" 1866: 8)

Prof. Blot distinguishes bloatedness from the "plumpness of good health," thereby drawing a line between bodily states that indicated proper and improper nutrition. Similarly, the popular journal Prairie Farmer (usually known for its advice aimed at a rural audience) often allocated space to address health concerns:

Parents are inclined to look upon fat as an indication of good health. They like to see their infants and young children fat and plump. They do appear better than if lean and lank. ("Muscles of Infancy" 1876: 395)

In these cases, popular journals reflected both the dominant views of the medical establishment and of health reformers, but extended them much more widely than would have been possible without a mass market.

Similar to plumpness, the French term embonpoint (meaning "in good condition") was often associated with women's fashion and the idea of voluptuousness. However, it was also used in medical and popular journals to describe a healthy state of fatness. For example, an article in the Boston Medical and Surgical Journal associates embonpoint with plumpness: "But that the effect of sugar, unless counteracted by particular circumstances, is calculated to promote plumpness and embonpoint, all scientific French chemists are agreed" ("Editorials" 1865: 24). So ingrained in dominant culture was the association of plumpness with good health that the decline of embonpoint signaled a descent into illness: 


\begin{abstract}
A blonde, in the most vigorous of health when she began to work at the machine, in seven or eight months had become enfeebled, her embonpoint was gone, her general health had declined, and she had become the subject of a profuse leucorrhea, which was daily increasing. ("Editorials" 1866: 87)
\end{abstract}

Thus, plumpness and embonpoint were linked with health and well-being. In this respect, past research is correct to suggest that fatness was valued in the nineteenth century. However, fatness could also be the cause of ill health, and much was written about the undesirable state of corpulence.

\title{
Corpulence
}

To be certain, corpulence was not plumpness. From a modern perspective, these terms might represent synonyms describing fatness-albeit one considered more polite (plump) and one considered anachronistic (corpulent). But to nineteenth-century doctors writing in medical journals, these categories were distinct and symbolized grave differences in a patient's health. In a treatise against the dangers of excessive drinking ("Malt Liquors" 1830), a writer in the Journal of Health warns:

\begin{abstract}
Malt liquors, when of a good quality, and drunk in moderation, constitute, for many persons, an innocent and wholesome beverage. Their immoderate use is attended, however, with the most injurious consequences. They who indulge in malt liquors to excess, become in general corpulent from languid circulation; but the fat which accumulates, often to a great extent, is very unhealthy. (212)
\end{abstract}

Corpulence, in this example, is linked with "languid circulation," a physiological disorder thought to arise from inactivity. Movement, ideally done outdoors, was believed to stimulate breathing and air intake, thereby increasing blood flow and improving health (Green 1986). Any condition that prohibited movement, including fatness understood as corpulence, was seen negatively—although it was necessary to make this distinction for readers, given that plumpness was a sign of health.

While a problem unto itself, corpulence also indicated the possible presence of diseases such as diabetes. As a physician in the late nineteenth century notes: "There exists an intimate connection between excessive fat-formation and sugar-secretion. Corpulence, especially in the young, is often a forerunner of diabetes" ("On Diabetes" 1875: 217). Yet, proscriptions against bodily fat were not only for the young-older men were also targets, and physicians offered no sympathy for the aged. In an article about the benefits of vigorous exercise to combat the effects of urban living, Dr. Duckworth (1897) comments:

I allow that there is instinctively a growing disinclination for the activities that were formerly attractive and pleasant earlier in life, and a tendency to grow stout, perhaps corpulent, especially below the belt, at the time of life I allude to. But it is not to be accepted or encouraged. I appeal now to the wives and sisters of such 
men as I describe, and must ask them to urge their better halves or their brothers to take sufficient active exercise, and to have pride in their figures.... For this is regrettable, truly a sign of degeneration, and not, in most instances, indicative of vigor of body. (428)

Similar to the worry about young boys' health because of industrial life, doctors extended their concern to aging men as well. Indeed, no one was exempt from needing to defend against the influence of city living, as too much body weight might indicate debility.

Such correlations of fatness and disease also found expression among health reformers who used alarmist language to promote their particular health system. In a then widely read pamphlet titled, Letter on Corpulence (1864), William Banting details the consequences of bodily fatness:

Corpulence, though giving no actual pain, as it appears to me, must natural press with undue violence upon the bodily viscera, driving one part upon another, and stopping the free action of all. (22)

Echoing the widespread warnings against malt liquor mentioned in the preceding text, Banting worried about fatness that inhibited the "free action" of both external limbs and internal organs. As with other writers of his day, Banting associated fatness that was considered unhealthy with obesity:

Of all the parasites that affect humanity I do not know of, nor can I imagine, any more distressing than that of obesity, and, having just emerged from a very long probation in this affliction, I am desirous of circulating my humble knowledge and experience for the benefit of my fellow man. (7)

Banting's use of terms like affliction and parasitic, as well as his later description of the "disease of obesity" (38), heightened the panic around fatness during a time when it might otherwise have been labeled as plumpness.

Banting was not the only health reformer to rail against bodily fatness, and many spoke about the dangers of obesity using moralizing language. For example, the "Water Cure" was a popular technique in the nineteenth century for treating a variety of ailments, and involved bathing, showering, or being sprayed with cold water. Such treatments were also thought to have an effect on body fat, and the journal associated with the movement-The Water-Cure Journal—assured readers that reducing unwanted fat was the key to health:

But these are not the only evils resulting from extreme obesity. The due action of the heart being prevented by the load of fat on its surface, the circulation of the blood becomes disordered, the breathing also is rendered laborious, and a constant tendency exists to palpitation or drowsiness, and every hour there is danger of apoplexy being excited, either spontaneously or from any slight cause. (“Corpulency” 1847: 205) 
Such advice, mixed as it was with moral overtones, constructed fatness not only as unhealthy, but as an evil to be purged from the body.

Popular press journals also treated corpulence as a problem in need of solving, although with somewhat less incendiary rhetoric. Still, the dominant belief at the time was that one's mind and body were intimately connected - a sound mind led to a healthy body, just as an unhealthy body indicated a weakened mind. A writer in Scientific American notes these associations in an article about food, intelligence, and social class:

Dr. Chambers, of London, in a recent lecture before the Royal College of Physicians, on the subject of corpulency, considered it in light of a hereditary disease, and endemic in several countries.... Dr. Chambers believes that the middle and upper classes of England eat a great deal too much food, and their moral and mental health is affected thereby, and the doctors do not insist enough on this branch of hygiene.... ("Fat People" 1852: 210)

The suggestion that individuals' intellect and morality could be negatively impacted due to food intake and body fat was both common knowledge and quite worrisome to middle- and upper-class people. Still, popular journals regularly relayed this type of warning, often accompanied by stern language that drew from medical writing and health reform ideologies:

The epitome of welfare is leanness; while the origin of evil, nay, evil itself, is fat.... For, it appears, it is only a vulgar error to believe that an increase of what is called good plight is any symptom of improving health. As an over-sanguine temperament is dangerous; as daily accidents occur from the undue predominance of the nervous systems, so does the extra-ordinary development of fat cause first inconvenience, then infirmities, and finally constitutes a malady hitherto considered incurable, and known as obesity. ("Excessive Fatness" 1857: 6)

Here, the author's intent is to convey the morality of body fat as "evil itself," while connecting such pronouncements to medical language involving the nervous system and the "disease" of obesity. As is evident from the preceding excerpts, fatness-when understood as corpulence—-was not valued in nineteenth-century thought.

\section{Leanness}

Just as nineteenth-century doctors drew distinctions between healthy and unhealthy fatness, they drew similar distinctions between healthy and unhealthy thinness. Unlike plumpness, which was generally seen positively throughout the 1800s, thinness was viewed with more skepticism. While a variety of terms were used to describe thinness, the ideas of leanness or slenderness often appeared in medical journals to denote

2. Although the term welfare today is often associated with government assistance for poverty, the term is used here to indicate general well-being or health. The term plight means the condition or state of good health. 
someone who was thin, but thought to be in good health. For example, an article in the Journal of Health explains how a patient is transformed through weight loss:

The shape of the body is likewise improved; any ungraceful protuberance of the abdomen is reduced.... In fact, as an able writer has correctly remarked, the nature of the human frame is, in a certain sense, totally altered, and in a very short space of time, the form, the character, and the powers of the body are completely changed, from gross to lean, from debility to vigorous health, and thus the very same individual, who but a few months before became giddy and breathless, on the least exertion, has his health not only improved, but is frequently enabled to run many miles, with the fleetness of a grey hound.... ("Effects of Training" 1832: 298)

Similarly, a writer in the Medical and Surgical Reporter recommends that patients exercise to remain healthy, and to reduce any unwanted bodily fat:

The best method of getting thinner consists in gradually withdrawing from the body that whereof there is superfluity, and in strengthening at the same time those parts which had been expanded. Bodily exercise will undoubtedly prove very advantageous, as we see stout horses getting lean by heavy work. ("Leyden" 1886: 79)

Doctors often associated leanness not only with healthiness through direct statements about its benefits, but also through natural imagery involving animals. The picture of the lean, fast greyhound or the lean workhorse likely stood out prominently in reader's minds and served to reinforce the medical view that thinness-alongside plumpness - could indicate health.

Health reformers, too, touted the benefits of leanness, as illustrated by an 1838 essay in the Graham Journal of Health and Longevity:

We are decided admirers of leanness. Our greatest characters are usually lithe,
attenuated men; stomachless, meager, lean, and lath-like beings, who have spir-
itualized themselves by keeping matter in subordination to mind. A corpulent
intellectualist is a contradiction in terms.... Obesity is a deadly foe to genius....
("Leanness Versus Obesity" 1838: 319)

Grahamism, or the philosophical and dietetic teachings of Sylvester Graham, was a popular target for medical writing, primarily because the strict vegetarian regimen produced rather thin devotees. Here, the authors-presumably Grahamites-conjure the specter of obesity and corpulence, thereby promoting leanness without disparaging plumpness. Similarly, a writer in The Water-Cure Journal recommends that patients eat potatoes to slim down:

Few are aware of the great value of the potato as an article of diet. It may astonish some of our readers when we assert that potatoes alone are sufficient to sustain the human body in a state of firm and vigorous health.... Lean men grow fat, and 
fat men become lean-lean as they ought to be. And so all grow better in health. ("Potato Diet" 1849)

Here, the author suggests that individuals might—-through proper diet—grow lean, but specifically "lean as they ought to be," thereby supporting the idea of a natural set point for healthy weight. And, according to some reform ideology at this time, that healthy point was one of bodily leanness.

Popular journals also praised leanness, particularly near the end of the nineteenth century when losing weight had risen in popularity. As an article titled "Fat and Lean People" (1870) explains:

It is a striking fact that most people want to weigh more than they do, and measure their health by their weight, as if a man were a pig, valuable in proportion to his heaviness.... Thin men the world over, are wiry and hardy; thin people live the longest.... Still there is a medium between being fat as a butterball and as thin and juiceless as a rail. (165)

In this example, all views of body weight in the nineteenth century are reconciled: The newer interest in slimming is supported, excessive fatness (or corpulence) is derided, and some middle ground is exonerated as beneficial. Even in children and infants, leanness was seen as a potentially positive state of health:

Feel of a kitten, calf, colt, or a young robin - they are and remain while growing little more than skin and bones and fur or feathers, because unable to get enough to fatten, and they never die-rarely have any sort of disease. Children are never fairly "out of the woods" until they reach the lean age and have pipe-stem legs and arms, with no roles of fatty tissue anywhere about them. Could they be kept so from birth and not permitted to over-indulge... they would have no infantile diseases to enrich our pockets. ("Should a Baby Be Fat?" 1881: 55)

Concern with the weight of infants ran the gamut from praising fleshy babies to casting lean babies as disease-fighting paragons. As is clear, a wealth of information about appropriate and inappropriate body weight assailed the nineteenth-century reader. Yet, a variety of healthy weight locations were recognized and encouraged.

\section{Gauntness}

Although thinness was not necessarily considered a medical issue unto itself, the threat of emaciation or gauntness hovered over the nineteenth-century body nearly constantly. Thinness was worrisome because it carried with it the possibility of disease or poverty, and medical journals routinely published articles warning people about the causes of gauntness. As noted in an essay about soldiers' low states of health due to the "red tape" of army bureaucracy, such causes were seen as the outcome of nutritional deficiencies, often rooted in social and structural issues: 
The unfortunate consequences of all this fell upon the unhoused, poorly fed, famished, and wornout men of the ranks, as well as the sick and wounded, who, instead of having a reception, a home-coming worthy of the service they have rendered their country, were obliged to drag their gaunt and shattered frames to their designated camping ground where insufficient tents awaited them and the long familiar nauseating rations which their enfeebled stomachs were powerless to digest. ("Red Tape" 1898: 310)

Gauntness was usually associated with physical weakness due to malnourishment, and when occurring within the military, became a problem of national strength. Gauntness was also considered serious when applied to young boys and girls, as illustrated in an 1845 essay on calisthenics:

Parents should avail themselves of the important benefits of this well-managed [calisthenics] academy, and allow their children to sport and grow in the full enjoyment of its gymnastic exercises. Once a week is better than nothing; and all the little feebly-organized pale-faced misses, and gaunt, lank, white-faced boys, in the city, should be put under Dr. Thayer's guidance. The academy also holds out one of the surest remedies for shop-worn clerks, indolent students, and those literary appendages of society who only exercise the brain. The muscles were designed to be used-every one of them; and when nature's intentions are fulfilled to the letter, a broad chest, round limbs, an erect stature, good lungs, bright eyes, red cheeks, health and happiness, are pretty sure to follow. ("Calisthentic Academy" 1845: 243)

Again, the anxiety over children who were weak from idleness and staying indoors appears in this passage, illustrating a common worry about city life and health.

Just as doctors in medical journals warned about the dangers of gauntness, so too did health reformers differentiate between healthy and unhealthy thinness. Conjuring images of diseased bodies, writers often connected gauntness with death: "There is a dread disease, which so prepares its victims, as it were, for death... a disease in which death and life are strangely blended, that death takes the glow of life and hue of life, and life the gaunt and grisly form of death" ("Consumption" 1848: 101). Gauntness was also frequently associated with emaciation and was a worrisome condition due to the connection between weight loss and disease. However, given the multiple meanings of body weight in the nineteenth century, it was often necessary to explain one's position if, for example, a noted health reformer championed leanness while deriding corpulence. Sylvester Graham's reply to a follower who had adopted his vegetarian program and become "a good deal emaciated and quite feeble" ultimately blames the condition on gluttony, not leanness:

If by the Graham system nothing more is meant than a diet of vegetable food and water without any regard to quantity, it is almost certain that nearly all who adopt it will break down or suffer much indisposition.... But this breaking down is not from the want of the nourishment of animal food, but is entirely from the excess in quantity of vegetable food. Gluttony and not starvation is the greatest of all causes of evil [emphasis in original].... (Graham 1838: 161) 
Graham's reply manages to praise thinness as a by-product of his system, while blaming overindulgence in quantity. This supported his temperance ideology of moderation, and allowed him to ward off medical criticisms of his thinner followers.

Popular journals also used the image of gauntness, often alongside warnings about fatness. As Dr. Dio Lewis (1870) in the Saturday Evening Post comments: "Even in New England there are a great many uncomfortably fat people. I say even in New England, because it is supposed that Yankees are a gaunt, ghostly folk" (4). Associating gauntness with images of death (i.e., "ghostly folk"), while also describing fatness as "uncomfortable," makes it clear that both fatness and thinness could be seen as negative in the nineteenth century. At the same time, gauntness did not always necessarily indicate emaciation, per se, but rather a lack of fat. This was, however, still not seen as healthy, given that fat in the form of plumpness was considered beneficial. In the popular imagination, this sentiment surfaced through storytelling when a character could be large, muscular, and gaunt simultaneously:

\begin{abstract}
In spite of all the magnificent muscular development which this man possessed, there was nothing of the Hercules about him. The grace of strength was wanting, the curve lines were lacking; all was gaunt, angular, and square. The chest was broad enough, but flat, a frame-work of bones hidden by a rough hairy skin. (Jeffries 1874: 110)
\end{abstract}

The author of this passage goes to great lengths to describe the man as having a degree of socially desired musculature, but not the plumpness associated with health. In this way, although an individual might possess some valued physical traits while lacking others, such bodily states were not mutually exclusive.

Given the preceding data, it is evident that nineteenth-century medical thought allowed for a continuum of weight and health, with both fatness and thinness being seen positively and negatively. It is also clear that body weight was already medicalized throughout the 1800s, as doctors routinely made assessments using body weight as one indicator of health. But, conflicting discourses from the institution of medicine, from health reform movements, and within popular culture competed to construct body weight as a public health concern. Indeed, nineteenth-century thought was far from consolidated about the ill or beneficial effects of one's weight. As noted earlier, however, this changed when multiple factors effected a cultural turn toward thinness at the beginning of the twentieth century, thereby solidifying the idea of bodily fat as dangerous and deadly.

\title{
Conclusion
}

Understanding the multiple symbolic positions held by body weight in the past requires investigation of medical, health reform, and popular sources. Within nineteenth-century thought, the categories of plumpness, corpulence, leanness, and 
gauntness constituted variable locations on a spectrum of health. Individuals could be thin and healthy (lean), thin and unhealthy (gaunt), fat and healthy (plump), or fat and unhealthy (corpulent). However, fatness as a potential state of health largely fell away at the beginning of the twentieth century, as medical thought consolidated around the idea that "excess" weight was a health risk. Up until that point, a variety of healthy and unhealthy weight locations were allowed to flourish, with supporters and detractors on both sides of the debate. As the extant literature suggests, the turn toward thinness in the early 1900s did bring about a noteworthy devaluing of fatness (Schwartz 1986; Stearns 1997). What makes this shift particularly interesting to study involves its impact on ideals regarding health and embodiment that have persisted to the contemporary era-ideals involving thinness, muscle tone, and extremely low bodily fat (Dworkin and Wachs 2009).

The implications of this research are multiple. First, it illustrates that differing views of body weight are not explainable due to fights within the medical community or between physicians and health reformers. As has been shown, many doctors considered fatness and thinness to be equally viable states of health, just as did health reformers. While professionalizing physicians often worked tirelessly to discredit health reform movements and consolidate authority (Porter 1988), their perspectives on body weight were more similar than different. Even after the establishment of the American Medical Association in 1847 and legal attempts to standardize US medical education (Conrad and Schneider 2005), the belief that fatness could indicate healthiness persisted until the beginning of the twentieth century. Thus, the struggle over credibility in nineteenth-century medicine did not involve championing a particular view of body weight.

Second, these findings suggest that fatness and thinness became solidified as dichotomous health opposites around the turn of the century. Certainly, they were already considered opposites in terms of size and shape, with numerous cartoons lampooning both the very thin and the very fat (Farrell 2011). However, thinness and fatness were not necessarily contrasting states of health. As evidenced by the multiple meanings of body weight in the nineteenth century, fatness and thinness coexisted and could indicate healthiness or unhealthiness equally. That is, being thin did not guarantee a clean bill of health, just as being fat did not condemn one to a diagnosis of debility.

Third, the turn of the twentieth century heralded more than just the solidification of fat and thin as health opposites, but also the loss of "plumpness" as a possible category of well-being. Thinness, in the forms of both leanness and gauntness, continued to represent either healthy or unhealthy weight. However, fatness - in all varietieswas declared unhealthy. Many factors played a role in this turn toward thinness, such as a growing skepticism of "abundance" in US society (Schwartz 1986), changes in the fashion industry (Stearns 1997), and the growth of the efficiency and scientific management movement (Haber 1964). Additionally, medical thought regarding fatness solidified near the beginning of the twentieth century when Dr. Brandreth Symonds released a 1908 report linking body weight with mortality rates (Czerniawski 2010). Accordingly, body weight that was previously understood as the healthy and 
unproblematic category of "plump" transformed into the medically problematic category of "overweight."

Such historical changes in the meaning of body weight may have also influenced contemporary assessments, as individuals with body weights above "Normal" on the Body Mass Index (BMI) are urged to diet and exercise into the Normal range. Modern understandings of body weight-filtered through the categories of the BMI—clearly demarcate "excess" through the "Overweight" and "Obese" labels and provide little room for designations of health outside the Normal category. The accuracy of such labels for indicating health has been called into question by recent research illustrating that the Overweight category carries no additional risk of death (Flegal et al. 2013) and may even provide health benefits (Carnethon et al. 2012; Doehner et al. 2010; Lainscak et al. 2012; Romero-Corral et al. 2006). But, without a conceptualization of fatness as potentially healthy, as was available in the nineteenth century, body weights above the standardized norm continue to be stigmatized in everyday interactions (Puhl and Heuer 2009; Saguy 2013).

When historical accounts are used as the backdrop for contemporary studies of weight, fatness is typically framed as a valued bodily state throughout most of the 1800 s. Yet, as the present research has shown, this is not an entirely accurate portrayal of fatness in the nineteenth century. The view that fatness was largely valued in the past represents only one side of the symbolic position held by body weight. Indeed, fatness as a stigmatized state has a long history that exists alongside more positive evaluations of plumpness. Such findings speak to the complexity of ideas in any given time period and suggest the need for future research to fully investigate the multifaceted and sometimes contradictory meanings of historical subjects. For now, the present study has highlighted how body weight held multiple symbolic positions in the nineteenth century, illustrating that medical opinion was far from consolidated about the negative effects of fatness, or the unequivocally positive effects of thinness.

\section{References}

(1830) "Malt Liquors." Journal of Health 1 (14): 212.

(1832) "Effects of Training." Journal of Health 3 (19): 298.

(1838) "Leanness Versus Obesity." The Graham Journal of Health and Longevity 2 (20): 319.

(1845) "Calisthenic Academy." The Boston Medical and Surgical Journal 33 (12): 242.

(1847) "Eating." The Water-Cure Journal 4 (5): 322.

(1847) "Corpulency." The Water-Cure Journal 4 (1): 205.

(1848) "Consumption." The Water-Cure Journal 6 (4): 101.

(1849) "Potato Diet." The Water-Cure Journal 7 (4): 114.

(1852) "Fat People." Scientific American VII (27): 210.

(1857) "Excessive Fatness: Its Dangers and Its Cure." Saturday Evening Post, May 23: 6.

(1865) "Editorials and Medical Intelligence." Boston Medical and Surgical Journal 72 (1): 24-28.

(1866) "Editorials and Medical Intelligence." Boston Medical and Surgical Journal 75 (4): 87-92.

(1866) "Remarks on Eating." Saturday Evening Post, June 23: 8. 
(1870) "Fat and Lean People." Prairie Farmer 41 (21): 165.

(1875) “On Diabetes." Medical and Surgical Reporter 33 (11): 217.

(1876) "Muscles of Infancy." Prairie Farmer 47 (50): 395.

(1881) "Should a Baby Be Fat?" Scientific American XLIV (4): 49.

(1886) "Leyden on the Treatment of Obesity." Medical and Surgical Reporter 55 (3): 79.

(1898) "Red Tape, the Stumbling-Block of the Army." Medical News 73 (10): 309.

(1952) "Fat \& Unhappy." Time, June 23: 64-66.

(1953) "34 Million Fatties.” Time, March 23: 67-68.

Allison, David B., Kevin R. Fontaine, JoAnn E. Manson, June Stevens, and Theodore B. VanItallie (1999) "Annual Deaths Attributable to Obesity in the United States." Journal of the American Medical Association 282 (16): 1530-38.

Altheide, David L. (1996) Qualitative Media Analysis. Thousand Oaks, CA: Sage.

Ashburner, John (1833) "Medicinal Virtues of the Smilax Aspera." The Boston Medical and Surgical Journal 9 (3): 01-04.

Banner, Lois (1983) American Beauty. New York: Knopf.

Banting, William (1864) Letter on Corpulence, Addressed to the Public. London: Harrison.

Brumberg, Joan Jacobs (1988) Fasting Girls: The Emergence of Anorexia Nervosa as a Modern Disease. Cambridge, MA: Harvard University Press.

Carnethon, Mercedes R., Peter John D. De Chavez, Mary L. Biggs, Cora E. Lewis, James S. Pankow, Alain G. Bertoni, Sherita H. Golden, Kiang Liu, Kenneth J. Mukamal, Brenda Campbell-Jenkins, and Alan R. Dyer (2012) "Association of Weight Status with Mortality in Adults with Incident Diabetes.” Journal of the American Medical Association 308 (6): 581-90.

Conrad, Peter, and Joseph W. Schneider (1992) Deviance and Medicalization: From Badness to Sickness. Philadelphia: Temple University Press.

(2005) "Professionalization, Monopoly, and the Structure of Medical Practice," in Peter Conrad (ed.) The Sociology of Health and Illness. New York: Worth Publishers: 170-76.

Crandall, Christian S. (1994) "Prejudice Against Fat People: Ideology and Self-Interest." Journal of Personality and Social Psychology 66 (5): 882-94.

Czerniawski, Amanda M. (2007) "From Average to Ideal: The Evolution of the Height and Weight Table in the United States, 1836-1943." Social Science History 31 (2): 273-96.

(2010) “Commentary: Symonds' Curious Fat Fact.” International Journal of Epidemiology 39 (4): 957-59.

de Castell, Suzanne, Alan Luke, and Kieran Egan (1986) "On Defining Literacy," in Suzanne de Castell, Alan Luke, and Kieran Egan (eds.) Literacy, Society, and Schooling: A Reader. New York: Cambridge University Press: 3-14.

DeJong, William (1980) "The Stigma of Obesity: The Consequences of Naive Assumptions Concerning the Causes of Physical Deviance.” Journal of Health and Social Behavior 21 (1): 75-87.

Dinh, Julie (2012) "From Voluptuous Woman to Porky Butterball: The Rise and Fall of the Voluptuous Woman Ideal." Constellations 3 (2): 187-93.

Dion, Karen, Ellen Berscheid, and Elaine Walster (1972) "What Is Beautiful Is Good.” Journal of Personality and Social Psychology 24 (3): 285-90.

Doehner, Wolfram, Andrew Clark, and Stefan D. Anker (2010) "The Obesity Paradox: Weighing the Benefit." European Heart Journal 31 (2): 146-48.

Duckworth, Sir Dyce (1897) "On the Value of Athletic Exercise as a Counter-Agent to the Sedentary Pursuits of Urban Populations." The American Journal of the Medical Sciences 114 (4): 424-34.

Duncan, Thomas Cation (1878) How to Be Plump, or Talks on Physiological Feeding. Chicago: Duncan Brothers.

Dworkin, Shari L., and Faye Linda Wachs (2009) Body Panic: Gender, Health, and the Selling of Fitness. New York: New York University Press.

Emerson, Robert M., Rachel I. Fretz, and Linda L. Shaw (1995) Writing Ethnographic Fieldnotes. Chicago: University of Chicago Press. 
Fairclough, Norman (2013) Critical Discourse Analysis: The Critical Study of Language. New York: Routledge.

Farrell, Amy Erdman (2011) Fat Shame: Stigma and the Fat Body in American Culture. New York: New York University Press.

Flegal, Katherine M., Barry I. Graubard, David F. Williamson, and Mitchell H. Gail (2005) "Excess Deaths Associated with Underweight, Overweight, and Obesity." Journal of the American Medical Association 293 (15): 1861-67.

Flegal, Katherine M., Brian K. Kit, Heather Orpana, and Barry I. Graubard (2013) "Association of AllCause Mortality with Overweight and Obesity Using Standard Body Mass Index Categories." Journal of the American Medical Association 309 (1): 71-82.

Graham, Sylvester (1838) "Excessive Alimentation, or the Propensity of People to Over-Eat." The Graham Journal of Health and Longevity 2 (11): 161.

Green, Harvey (1986) Fit for America: Health, Fitness, Sport and American Society. Baltimore, MD: The John Hopkins University Press.

Haber, Samuel (1964) Efficiency and Uplift: Scientific Management in the Progressive Era, 1890-1920. Chicago: University of Chicago Press.

Hamermesh, Daniel S. (2011) Beauty Pays: Why Attractive People Are More Successful. Princeton, NJ: Princeton University Press.

Hutson, David J. (2009) "From Morality to Muscles: The Changing Meaning of Exercise in NineteenthCentury America." Unpublished Master's Thesis, University of Michigan, Ann Arbor.

_ (2013) "'Your Body Is Your Business Card': Bodily Capital and Health Authority in the Fitness Industry." Social Science and Medicine 90: 63-71.

Jeffries, Richard (1874) “John Smith’s Shanty.” Prairie Farmer 45 (14): 110.

Kwan, Samantha, and Mary Nell Trautner (2011) "Weighty Concerns." Contexts 10 (2): 52-57.

Lainscak, Mitja, Stephan von Haehling, Wolfram Doehner, and Stefan D. Anker (2012) "The Obesity Paradox in Chronic Disease: Facts and Numbers." Journal of Cachexia, Sarcopenia and Muscle 3 (1): $1-4$.

Levenstein, Harvey (2003) Paradox of Plenty: A Social History of Eating in Modern America. Berkeley: University of California Press.

Lewis, Dio (1870) "Fat and Thin People." Saturday Evening Post, October 1: 4.

Mokdad, Ali H., Mary K. Serdula, William H. Dietz, Barbara A. Bowman, James S. Marks, and Jeffrey P. Koplan (1999) "The Spread of the Obesity Epidemic in the United States, 1991-1998." Journal of the American Medical Association 282 (16): 1519-22.

Park, Roberta J. (1989) "Healthy, Moral, and Strong: Educational Views of Exercise and Athletics in Nineteenth-Century America," in Kathryn Grover (ed.) Fitness in American Culture. Amherst: University of Massachusetts Press: 123-68.

Paul, James (1865) "The Food and the Teeth.” Medical and Surgical Reporter 13 (13): 01-07.

Porter, Roy (1988) "Before the Fringe: 'Quackery' and the Eighteenth-Century Medical Market," in Roger Cooter (ed.) Studies in the History of Alternative Medicine. London: Palgrave Macmillan: 1-27.

Puhl, Rebecca M., and Chelsea A. Heuer (2009) “The Stigma of Obesity: A Review and Update.” Obesity 17 (5): 941-64.

Rhode, Deborah L. (2010) The Beauty Bias: The Injustice of Appearance in Life and Law. New York: Oxford University Press.

Romero-Corral, Abel, Victor M. Montori, Virend K. Somers, Josef Korinek, Randal J. Thomas, Thomas G. Allison, Farouk Mookadam, and Francisco Lopez-Jimenez (2006) "Association of Bodyweight with Total Mortality and with Cardiovascular Events in Coronary Artery Disease: A Systematic Review of Cohort Studies." The Lancet 368 (9536): 666-78.

Saguy, Abigail C. (2013) What's Wrong with Fat? New York: Oxford University Press.

Saguy, Abigail C., and Kjerstin Gruys (2010) "Morality and Health: News Media Constructions of Overweight and Eating Disorders." Social Problems 57 (2): 231-50.

Schwartz, Hillel (1986) Never Satisfied: A Cultural History of Diets, Fantasies, and Fat. New York: The Free Press. 
Stahlberg, (1877) "Cases of Sickness Treated at the Kumyss Institution, at Moscow." Medical and Surgical Reporter 37 (8): 143-47.

Stearns, Peter N. (1997) Fat History: Bodies and Beauty in the Modern West. New York: New York University Press.

Strauss, Anselm, and Barney G. Glaser (1967) The Discovery of Grounded Theory: Strategies for Qualitative Research. Chicago: Aldine.

Symonds, Brandreth (1908) "The Influence of Overweight and Underweight on Vitality." Journal of the Medical Society of New Jersey 5 (4): 159-67.

Taylor, Frederick W. (1911) The Principles of Scientific Management. New York: Harper and Brothers.

Tebbel, John, and Mary Ellen Zuckerman (1991) The Magazine in America, 1741-1990. New York: Oxford University Press. 